\title{
Potential Value of miR-221/222 as Diagnostic, Prognostic, and Therapeutic Biomarkers for Diseases
}

\author{
Jialin Song ${ }^{1,2 t}$, Yuanming Ouyang ${ }^{1,2 t}$, Junyi Che ${ }^{3}$, Xiaoming Li $^{3}$, Yi Zhao ${ }^{3}$, Kejia Yang ${ }^{3}$, \\ Xiaotian Zhao ${ }^{3}$, Yinghui Chen ${ }^{4 *}$, Cunyi Fan ${ }^{1 *}$ and Weien Yuan ${ }^{3 *}$

\begin{abstract}
'Shanghai Jiao Tong University Affiliated Sixth People's Hospital, Shanghai, China, ${ }^{2}$ Shanghai University of Medicine \& Health, Shanghai Sixth People's Hospital East Campus, Shanghai, China, ${ }^{3}$ School of Pharmacy, Shanghai Jiao Tong University, Shanghai, China, ${ }^{4}$ Department of Neurology, Jinshan Hospital, Fudan University, Shanghai, China
\end{abstract}

OPEN ACCESS

Edited by: Kai Fang, University of California Los Angeles,

Reviewed by:

Francesca Lovat,

Ohio State University, USA

Satoshi Fukushima,

Kumamoto University, Japan

${ }^{*}$ Correspondence:

Yinghui Chen

cyh1973131@163.com;

Cunyi Fan

fancunyi888@163.com;

Weien Yuan

yuanweien@126.com

tThese authors have contributed equally to this work.

Specialty section:

This article was submitted to Inflammation,

a section of the journal

Frontiers in Immunology

Received: 21 October 2016 Accepted: 13 January 2017 Published: 16 February 2017

Citation:

Song J, Ouyang Y, Che J, Li X, Zhao $Y$, Yang $K$, Zhao $X$, Chen $Y$, Fan $C$ and Yuan W (2017) Potential Value of miR-221/222 as Diagnostic,

Prognostic, and Therapeutic

Biomarkers for Diseases.

Front. Immunol. 8:56.

doi: 10.3389/fimmu.2017.00056
microRNAs (miRNAs) are short non-coding RNAs that regulate gene expression by base pairing with their target messenger RNAs. Dysregulation of miRNAs is involved in the pathological initiation and progression of many human diseases. miR-221 and miR-222 (miR-221/222) are two highly homologous miRNAs, and they are significantly overexpressed in several types of human diseases. Silencing miR-221/222 could represent a promising approach for therapeutic studies. In the present review, we will describe the potential value of miR-221/222 as diagnostic, prognostic, and therapeutic biomarkers in various diseases including cancer and inflammatory diseases.

Keywords: microRNAs, miR-221/222, diseases, diagnosis, prognosis, therapy, biomarker

\section{INTRODUCTION}

microRNAs (miRNAs), a class of small (19-25 nt in length) single-stranded RNAs, are involved in posttranscriptional regulation of gene expression by base pairing with the complementary sequences in the $3^{\prime}$ untranslated region ( $3^{\prime}$ UTR) of their target messenger RNAs (mRNAs) $(1,2)$. miRNAs are generated from the transcription of a long precursor (primary miRNA), which is then processed to a stem-loop precursor miRNA (pre-miRNA) by the nuclear protein Drosha in the nucleus (3). The DiGeorge syndrome Critical Region 8 protein (DGCR8) serves as a molecular ruler, directing the cleavage of Drosha (4). The pre-miRNA of 60-100 nt in length is cleaved by endoribonuclease Dicer to mature miRNA and antisense miRNA star products after the transportation of pre-miRNA to the cytoplasm by exportin-5 (5). The mature miRNA is incorporated into a RNA-induced silencing complex, which results in the inhibition of translation or degradation of the target mRNAs by binding to partially complementary sites (6). It has been widely shown that dysregulation of miRNAs is associated with the initiation, development, and progression of cancer or other diseases (7-9). miR-221 and miR-222, encoded in tandem from a gene cluster located on X chromosome (Xp11.3), contain identical seed sequences separated by 727 bases and are highly conserved in vertebrates (10). In healthy conditions, they have been found to regulate essential physiological vascular processes such as angiogenesis, neointimal hyperplasia, vessel wound healing, vascular aging, and atherosclerotic vascular remodeling (11-14). These two highly homologous miRNAs are frequently acting as a gene cluster (miR-221/222) and have been extensively studied in many human malignancies. In this review, we focus on the current knowledge about the roles of miR-221/222 in the diagnosis, prognosis, and therapy for breast cancer, liver cancer, pancreatic cancer, prostate cancer, gastric cancer, colorectal cancer (CRC), glioma, multiple myeloma (MM), and inflammatory diseases (Table 1). 
TABLE 1 | Roles of miR-221/222 in human diseases.

\begin{tabular}{|c|c|c|c|c|c|}
\hline Cancer & Targets & Biological function & $\begin{array}{l}\text { Effects following microRNA antisense/inhibitor } \\
\text { therapy }\end{array}$ & Correlation & Reference \\
\hline Breast cancer & $\begin{array}{l}\text { TRPS1, ADIPOR, SOCS1, } \\
\text { CDKN1B, ER } \alpha, \text { p27, TIMP3 }\end{array}$ & $\begin{array}{l}\text { Epithelial-to-mesenchymal } \\
\text { transition (EMT), S-phase entry }\end{array}$ & $\begin{array}{l}\text { Restore ER } \alpha \text { expression and tamoxifen sensitivity; } \\
\text { decrease cell growth; increase apoptosis }\end{array}$ & Prognosis & $(15-20)$ \\
\hline Liver cancer & $\begin{array}{l}\text { Bone marrow failure, p27, } \\
\text { p57, HDAC }\end{array}$ & Cell growth, apoptosis & $\begin{array}{l}\text { Increase apoptotic cell death; decrease tumor } \\
\text { nodules }\end{array}$ & $\begin{array}{l}\text { Detection and } \\
\text { prognosis }\end{array}$ & $(21-24)$ \\
\hline $\begin{array}{l}\text { Pancreatic } \\
\text { cancer }\end{array}$ & $\begin{array}{l}\text { TIMP-2, PTEN, p27, p57, } \\
\text { and p53 upregulated } \\
\text { modulator of apoptosis } \\
\text { (PUMA), death receptor } \\
\text { 5, Bim }\end{array}$ & $\begin{array}{l}\text { Cell proliferation, cell invasion, } \\
\text { G1-phase arrest, apoptosis }\end{array}$ & $\begin{array}{l}\text { Decrease cell proliferation } \\
\text { Antitumor effect }\end{array}$ & $\begin{array}{l}\text { Detection and } \\
\text { prognosis }\end{array}$ & $(25-29)$ \\
\hline Prostate cancer & $\begin{array}{l}\text { p27, ARHI, SIRT1, HECTD, } \\
\text { RAB1A }\end{array}$ & $\begin{array}{l}\text { Cell cycle, apoptosis, androgen } \\
\text { receptor signaling, EMT }\end{array}$ & Decrease tumor growth; increase apoptosis & $\begin{array}{l}\text { Tumor stage } \\
\text { and prognosis }\end{array}$ & $(10,30-33)$ \\
\hline Gastric cancer & p27, p57, PTEN, RECK & Cell cycle progression & $\begin{array}{l}\text { Decrease cell proliferation and migration; increase cell } \\
\text { radiosensitivity }\end{array}$ & $\begin{array}{l}\text { Detection and } \\
\text { prognosis }\end{array}$ & $(34-38)$ \\
\hline $\begin{array}{l}\text { Colorectal } \\
\text { cancer }\end{array}$ & p57, RECK, PDLIM2, PTEN & Cell cycle & $\begin{array}{l}\text { Decrease proliferation; increase apoptosis; increase } \\
\text { radiosensitivity }\end{array}$ & $\begin{array}{l}\text { Detection and } \\
\text { prognosis }\end{array}$ & $(39-43)$ \\
\hline Glioma & $\begin{array}{l}\text { p27, p57, p53, РTP } \mu \text {, } \\
\text { TIMP3 }\end{array}$ & $\begin{array}{l}\text { Cell cycle, apoptosis, cell } \\
\text { migration, radio-induced DNA } \\
\text { damage repair }\end{array}$ & $\begin{array}{l}\text { Decrease tumor growth; increase apoptosis, } \\
\text { radiosensitivity }\end{array}$ & $\begin{array}{l}\text { Detection and } \\
\text { prognosis }\end{array}$ & $(33,44-49)$ \\
\hline $\begin{array}{l}\text { Multiple } \\
\text { myeloma }\end{array}$ & $\begin{array}{l}\text { p27, PUMA, PTEN, p57, } \\
\text { Ki-67 }\end{array}$ & Cell growth and apoptosis & $\begin{array}{l}\text { Antitumor activity, anti-proliferative effect, no organ- } \\
\text { related toxicity, restore melphalan sensitivity }\end{array}$ & $\begin{array}{l}\text { Detection } \\
\text { and genetic } \\
\text { subtype }\end{array}$ & $(50-53)$ \\
\hline $\begin{array}{l}\text { Malignant } \\
\text { melanoma }\end{array}$ & $\begin{array}{l}\text { p27Kip1/CDKN1B and the } \\
\text { C-KIT receptor } \\
\text { PI3K/AKT }\end{array}$ & $\begin{array}{l}\text { Differentiation and enhanced } \\
\text { proliferation of the melanoma } \\
\text { cells }\end{array}$ & $\begin{array}{l}\text { Proliferation, differentiation, apoptosis, and } \\
\text { angiogenesis }\end{array}$ & $\begin{array}{l}\text { Detection and } \\
\text { prognosis }\end{array}$ & $(54,55)$ \\
\hline $\begin{array}{l}\text { Rheumatoid } \\
\text { arthritis }\end{array}$ & $\begin{array}{l}\text { MMP-3, MMP-9, vascular } \\
\text { endothelial growth factor }\end{array}$ & Cell growth & $\begin{array}{l}\text { Inhibit pro-inflammatory cytokines and cell invasion; } \\
\text { increase cell apoptosis }\end{array}$ & Detection & $(56,57)$ \\
\hline Atherosclerosis & PGC-1a, AdipoR1 & $\begin{array}{l}\text { Reactive oxygen species (ROS), } \\
\text { cell apoptosis, NO synthesis }\end{array}$ & $\begin{array}{l}\text { Ameliorate inflammation-induced cellular ROS } \\
\text { production }\end{array}$ & Detection & $(58-61)$ \\
\hline
\end{tabular}

\section{BREAST CANCER}

In basal-like breast cancer, stimulated transcription of miR221/222 by basal-like transcription factor FOSL1 (Fos-like 1, also named Fra1) can promote epithelial-to-mesenchymal transition (EMT) via targeting the $3^{\prime} \mathrm{UTR}$ of trichorhinophalangeal 1 (TRPS1), leading to increased cell migration and invasion (15). Moreover, overexpressed miR-221/222 can promote the EMT in breast cancer by negatively regulating adiponectin receptor 1 (ADIPOR1) (16). Li et al. also reported that a significantly higher expression of miR-221/222 was observed in highly invasive basal-like breast cancer, which could contribute to S-phase entry, cellular migration, and invasion through the downregulation of suppressor of cytokine signaling 1 (SOCS1) and cyclin-dependent kinase inhibitor 1B (CDKN1B) (17). Studies also showed that miR-221/222 enhanced breast cancer growth, migration, and invasion, meanwhile propagating the self-renewal of breast cancer stem cells by targeting phosphatase and tensin homolog/Akt (PTEN/Akt) pathway (62).

Overexpression of miR-221/222 can contribute to estrogenindependent growth and fulvestrant resistance in breast cancer, which occurs together with $\beta$-catenin activation, dysregulation of transforming growth factor beta (TGF- $\beta$ )-induced growth inhibition and p27 suppression (63). Increased tamoxifen resistance in breast cancer is associated with the inhibition of p 27 regulated by elevating the expression of miR-221/222, and overexpression of p27 in the resistant cells can enhance their sensitivity to tamoxifen (64). Moreover, it has been reported that miR-221/222 negatively regulates estrogen receptor alpha $(\mathrm{ER} \alpha)$, and knockdown of miR-221/222 can partially restore ER $\alpha$ expression and tamoxifen sensitivity (65). Downregulated expressions of p27 and ER $\alpha$ can enhance tamoxifen resistance by secreting miR-221/222 in exosomes for ER-positive and tamoxifen-sensitive breast cancer cells (66). Inhibition of miRNA-221/222 in ER-positive human breast adenocarcinoma cell line (MCF-7) can also increase the sensitivity to tamoxifen through the upregulation of tissue inhibitor of metalloproteinases-3 (TIMP3) (18). Therefore, miR221/222 might serve as potential therapeutic targets for drug resistance in breast cancer.

Nucleolin, an integral component of the microprocessor complex consisting of Drosha and DGCR8, can regulate the expression of several miRNAs (such as miR-21, miR-221/222, and miR-103) that involved in breast cancer aggressiveness and drug resistance $(63,67-70)$. A specific aptamer AS1411 has been demonstrated to be able to modulate nucleolin binding to the microprocessor complex and affect the expressions of these above miRNAs by posttranscriptional regulation, thus reducing breast cancer metastasis both in vitro and in vivo (19). Moreover, nucleolin targeting treatment could also lead to decreasing cell growth and increasing apoptosis of fulvestrant-resistant breast cancer cells, thereby suggesting that targeting compounds of nucleolin has the potential to improve the sensitivity of drug resistant breast cancer 
cells in the clinical practice (19). Falkenberg et al. have reported that high expression of miR-221/222 is significantly associated with the occurrence of distant metastases in breast cancer, thereby suggesting that miR-221/222 may become promising markers for breast cancer prognosis (20).

\section{LIVER CANCER}

Upregulated expression of miR-221/222 is involved in the progression of liver fibrosis by the activation of stellate cells (71). Moreover, miR-221/222 overexpression is linked to liver tumorigenesis from normal liver through cirrhosis to full-blown hepatocellular carcinoma (HCC), and miR-221/222 can enhance cell growth by targeting the cyclin-dependent kinase inhibitor p27 (72, 73).

Many studies have demonstrated that miR-221 can increase cell growth, inhibit apoptosis, and promote tumor progression in $\operatorname{HCC}(72,74,75)$. miR-221 overexpression is able to inhibit apoptosis of HCC-derived cell lines by targeting bone marrow failure (BMF) syndromes, and increased apoptotic cell death can be caused by miR-221 silencing (21). The hypothesis that increased expression of miR-221 might posttranscriptionally downregulate BMF to affect the TGF- $\beta$ proapoptotic signals will require further investigations $(76,77)$. The increased expression of miR-221 contributes to the progression of liver cancer by downregulating the histone deacetylase (HDAC) through natural killer/cells-Jun (NK/c-Jun) activation and nuclear factor-kappa B p65 (NF-кBp65) nuclear translocation (22). Increase in miR-221 expression and repression of its target genes (such as proapoptotic BMF and cyclin-dependent kinase inhibitor p27/57) have been revealed in the liver of a miR-221 transgenic mouse model, and in vivo delivery of anti-miR-221 oligonucleotides can lead to significant reduction of the number and size of tumor nodules (23). The DNA hypomethylation at miR-221/222 locus and wildtype tumor repressor protein 53 (TP53) activation by targeting MDM2 (E3 ubiquitin protein ligase homolog) is confirmed to be contributors to miR-221 overexpression in clinical specimens of HCC (78). It has been found that miR-221 is a core miRNA, which targets lots of HCC-related genes by feed-forward regulatory loops combining transcription factors from bioinformatics analysis, and lentivirus-mediated miR-221 silencing can significantly suppress liver cancer cells as well as the growth of hepatoma xenografts in vivo (79).

Overexpressed miR-221 in serum samples of HCC patients correlates with tumor size, cirrhosis, tumor stage, and overall survival rate (24). An obvious relationship has been revealed between miR-221 levels in tissues and the migration, invasion, metastasis, tumor capsular infiltration, and time to recurrence after surgical resection of $\operatorname{HCC}(21,74)$. Hence, miR-221 may be valuable for the prognosis of HCC patients and the use of miRNA silencing technology appears to be a promising therapeutic approach for HCC.

\section{PANCREATIC CANCER}

Overexpressed miR-221/222 can contribute to the expression of matrix metalloproteinases-2 (MMP-2) and MMP-9 by directly targeting tissue inhibitor of MMP-2 (TIMP-2), thereby facilitating pancreatic cancer invasion (25). Transfection of pancreatic cancer cells with miR-221 inhibitor could inhibit cell proliferation by upregulation of phosphatase and tensin homolog (PTEN), p27, p57, and p53 upregulated modulator of apoptosis (PUMA) (26). Combination of chemotherapeutic drug sunitinib at low dosage and anti-miRNA oligonucleotides targeting the overexpressed miR-21, miR-221/222, and miR-10 can achieve notable synergistic antitumor effect in pancreatic ductal adenocarcinoma cells, thereby indicating that this combinatory approach might be of great importance for therapeutic applications in this disease (27). Moreover, Tanaka et al. reported that metformin could suppress the expression of miR-221, which was responsible for G1-phase arrest and apoptosis via the upregulation of $\mathrm{p} 27$, death receptor 5 , and Bim in pancreatic cancer cells (28).

In the specimens of pancreatic cancer tissue, miR-221 and miR-222 were confirmed to be significantly upregulated, thereby suggesting that these two miRNAs had the potential to be used as diagnostic biomarkers for pancreatic cancer $(80,81)$. In addition, elevated expression of miR-222 has been reported to be an independent predictor of poor prognosis of pancreatic cancer (29).

\section{PROSTATE CANCER}

It was reported that overexpression of miR-221/222 might contribute to the progression of prostate carcinoma through downregulating cell cycle inhibitor p27 (10) and aplasia ras homolog member I (ARHI), which influenced cell cycle and apoptosis $(82,83)$. Yang et al. observed an increase in SIRT1, cell proliferation, and apoptosis and decrease in migration reduction after transfecting PC-3 cells with miR-221/222 inhibitor, thereby suggesting that the tumor-promoting role of miR-221/222 might be mediated by the activation of silent information regulator two homolog one (SIRT1) (30). The in vivo study by Mercatelli et al. also confirmed that miR-221/222 inhibition could lead to the upregulation of p27 and reduce the tumor growth of preestablished prostate carcinoma xenografts, thereby indicating the therapeutic potential of miR-221/222 in prostate cancer (31). Wang et al. found that miR-221/222 promoted cell proliferation and repressed apoptosis of prostate cancer cells by repressing caspase-10, and prostate cancer cells were sensitized to tumor necrosis factor-a/cycloheximide (TNF- $\alpha / \mathrm{CHX}$ )-induced apoptosis after miR-221/222 knockdown (84).

Androgen receptor (AR) signaling has a critical role in the development and progression of prostate cancer (85). Many studies have found that miR-221/222 is important in tumorigenesis and progression from androgen-dependent to androgenindependent (castration-resistant) prostate cancer $(86,87)$. Upregulation of miR-221/222 has been observed in the tumor tissues of patients with castration-resistant prostate cancer (88). Moreover, miR-221/222 was involved in the progression from hormone-sensitive to castration-resistant prostate cancer by downregulating HECTD2 and RAB1A, which subsequently led to reprograming of AR signaling, and activation of EMT and new cyclins (32). 
The levels of miR-221/222 were significantly higher in aggressive prostate cancer tissue samples than in non-aggressive prostate cancer tissue samples (83). It has been concluded that elevated miR-221/222 expression is significantly associated with a poor overall survival for patients with prostate cancer (33).

\section{GASTRIC CANCER}

The expression of miR-222/221 is significantly higher in gastric tumor samples compared to the corresponding normal tissues, and miR-222/221 can enhance gastric tumor growth in the mouse xenograft model (34). Meanwhile, miR-221/222 can facilitate the cell cycle progression of gastric cancer cells by downregulating p27 and p57 (34). In addition, it has been indicated that increased miR-221/222 can significantly inhibit reversioninducing cysteine-rich protein with kazal motifs (RECK) whose aberrant methylation is useful for early diagnosis and treatment of peritoneal metastasis of gastric cancer, thereby resulting in enhanced proliferation and invasion of gastric cancer cells (35, 89). Knockdown of miR-221/222 with anti-miRNA oligonucleotides can inhibit cell growth, suppress cell invasion, and enhance cell radiosensitivity of human gastric cancer cells through the upregulation of PTEN (36). Xu et al. reported that antisense oligonucleotide targeting miR-21, miR-106a, and miR-221 could effectively inhibit the proliferation and migration of human gastric cancer cells (90). Therefore, modulation of miR-221/222 expression by antisense nucleic acid technology might be helpful for gene therapy of gastric cancer.

The increased expression of miR-221 in gastric cancer tissue samples is associated with advanced clinical stage, local invasion, lymphatic metastasis, and poor survival (91). The serum miR-221 has been identified to be a potential biomarker for early detection of gastric cancer and significantly positive correlated with poor differentiation of gastric cancer according to a population-based study (37). Furthermore, miR-222 in plasma is significantly correlated with clinical stages, lymph nodes metastasis, and overall survival (38). These data indicate that circulating miR-221/222 has potential diagnostic and prognostic values in gastric cancer.

\section{COLORECTAL CANCER}

Sun et al. have demonstrated that miR-221 significantly overexpressed in $90 \%$ of CRC samples, and the miR-221 expression is positively correlated with an advanced tumor node metastasis stage and local invasion (39). They also confirmed that miR221-specific inhibitor could markedly inhibit CRC cell proliferation and induce apoptosis by upregulating cyclin-dependent kinase inhibitor/p57 (CDKN1C/p57) (39). Moreover, miR-221 overexpression enhanced $\mathrm{CRC}$ cell invasion and metastasis through targeting RECK (40). It has been reported that miR$221 / 222$ can reduce the ubiquitination and degradation of RelA and activator of transcription 3 (STAT3) proteins by directly binding to 3'UTR of PDLIM2, and miR-221/222 inhibitors can reduce CRC cell proliferation and colony formation (41). Formation of fewer tumors was observed after the injection of lentiviruses expressing miR-221/222 sponges (miR-221/222) in the mice model of colitis. As a competitive inhibitor of small
RNAs in mammalian cells, miRNA sponges stably expressed miR-221/222 leading to reduced tumor volume and weight, as well as fewer Ki67-positive cells in tumors $(41,92)$. Moreover, inhibition of miR-221 could enhance the radiosensitivity of CRC cells by upregulating PTEN (42).

According to the study by $\mathrm{Pu}$ et al., plasma miR-221 is a potential diagnostic biomarker for differentiating CRC patients from controls and elevated plasma miR-221 level is a significant prognostic factor for poor overall survival in CRC patients (43). A survival analysis has also indicated that high expression of miR221 in colon cancer is closely associated with a shorter survival time (93). The levels of miR-221 in stool samples from subjects with CRC were significantly higher, and the area under the curve value of stool miR-221 was 0.73 , thereby suggesting that stoolbased miR-221 might be used as a potential detection biomarker for CRC (94).

\section{GLIOMA}

The enhanced expression of miR-221/222 in glioblastoma can promote S-phase entry by targeting the cell cycle inhibitors (p27 and p57), and knockdown of miR-221/222 strongly reduced tumor growth in vivo $(44,45)$. Upregulation of miR-221/222 inhibits cell apoptosis by targeting PUMA in human glioma cells (46). Moreover, miR-222/221 overexpression can promote cell migration and growth by downregulating the protein tyrosine phosphatase $\mu(\mathrm{PTP} \mu)$ in glioblastoma $(47,95,96)$. It was also found that miR-221/222 could regulate the invasion capability of glioma cells by directly targeting TIMP3 (33). Zhang et al. also reported that the plasma miR-221/222 family levels were found to be significantly upregulated in glioma patients, and high positive plasma miR-221 and miR-222 were both correlated with poor survival rate, which should be considered as a new additional tool to better characterize glioma (97).

Repression of miR-221 by a peptide nucleic acid could contribute to growth inhibitory effects via significant increase in p27 and TIMP3, thereby suggesting that sequence-selective targeting against miR-221 might have the potential for the treatment of human gliomas (98). Recently, administration of temozolomide in combination with radiotherapy was the best clinical approach for glioblastoma treatment $(99,100)$. Knockdown of miR-221/222 sensitized glioma cells to temozolomide and increased apoptosis in human gliomas by regulating apoptosis independent of the p53 status (48). The response to temozolomide is dependent on the intracellular level of the alkylating enzyme $\mathrm{O}^{6}$-methylguanineDNA methyltransferase (MGMT), and Quintavalle et al. have showed that downregulation of MGMT targeted by miR-221/222 may render cells unable to repair their genetic damage (101). It suggested that miR-221/222 could serve as potential therapeutic targets for radioresistance of glioblastoma cells since miR$221 / 222$ played a crucial role in radio-induced DNA damage repair and silencing of miR-221/222 could significantly increase radiosensitivity of glioblastoma cells by PTEN-independent inhibition of Akt (49). Moreover, the combined anti-miR-221/222 and radiotherapy is more efficient for the suppression of tumor growth than anti-miR-221/222 or radiotherapy alone in a murine glioblastoma model (49). 
The expression of miR-221/222 in high-grade gliomas is significantly increased compared with low-grade gliomas, and increased level of miR-221/222 is positively correlated with the degree of glioma infiltration that is associated with poorer overall survival (33). The study by Zhang et al. have demonstrated that plasma miR-221/222 levels are significantly upregulated in glioma patients and high plasma levels of miR-221/222 correlate with poor survival rate, thereby suggesting that miR-221/222 should be considered as prognostic biomarkers for glioma (97).

\section{MULTIPLE MYELOMA}

The expression of miR-221/222 was revealed to be upregulated in human myeloma cell lines and primary MM tumors, and miR$221 / 222$ of plasma cells was at higher levels in $t(4 ; 14)$ patients than in the other classes $(102,103)$. Silencing miR-221/222 by specific inhibitors could result in a powerful antitumor activity in MM cells bearing $\mathrm{t}(4 ; 14)$ and murine models of human MM via upregulation of p27, PUMA, PTEN, and p57 (50). At the same time, the antitumor activity of miR-221 inhibitors was higher than that of miR-222 inhibitors (50). The 13-mer locked nucleic acid-inhibitor-miR-221 (LNA-i-miR-221) had remarkable anti-proliferative effect on $\mathrm{t}(4 ; 14)$-translocated MM cells via strong derepression of $\mathrm{p} 27$, and significant antitumor activity against $\mathrm{t}(4 ; 14) \mathrm{MM}$ xenografts was also observed after 2 weeks of exposure to LNA-i-miR-221 with upregulated p27 and reduced Ki-67 (51). Meanwhile, neither behavioral changes nor organ-related toxicity was observed in mice after the exposure to LNA-i-miR-221 according to the pathology examination (51).

Moreover, it is urgently needed to develop novel therapeutic strategies for MM since this disease can commonly progress to drug-refractory end stage that remains an obstacle to longterm survival $(104,105)$. The expression level of miR-221/222 is negatively correlated with the melphalan sensitivity of MM cells, and miR-221/222 inhibition restores melphalan sensitivity and triggers apoptosis of $\mathrm{MM}$ cells with upregulation of proapoptotic Bcl-2-binding component 3 (BBC3)/PUMA, modulation of drug influx-efflux transporters SLC7A5/LAT1, and the ATP-binding cassette transporter multidrug resistance-associated protein 1 (ABCC1/MRP1) (52). The combined treatment of severe combined immunodeficient/non-obese diabetic mice bearing human melphalan-refractory MM xenografts with LNA-i-miR-221 and melphalan can also overcome drug resistance and induce antitumor activity, which is associated with upregulation of $\mathrm{BBC} 3 / \mathrm{PUMA}$ and downregulation of ABCC1 (52). Therefore, the miRNA-based therapies may be useful for clinical trials to overcome resistance in drug-refractory MM, especially miR-221. The miR-221 is confirmed to be significantly upregulated in the plasma samples of MM patients, and miR-221 is associated with chromosomal abnormalities, thereby suggesting that it has potential to be considered as clinical biomarkers for MM (53).

\section{MALIGNANT MELANOMA (MML)}

Malignant melanoma is a fatal and aggressive neoplasm. miR-221 is an abnormally expressed in MML cells, and it induces the malignant phenotype through downmodulation of p27Kip1/CDKN1B and the c-KIT receptor; and the significantly increased level of miR-221 in patients' circulating serum with MML is used as a new tumor marker, which is useful for the MML diagnosis, the in situ differentiating MML from stages I to IV MML, evaluating cancer progression, and monitoring patients during the follow-up period. In addition, the levels of miR-221 in serum are correlated with cancer thickness; miR-221 will be useful as a prognostic marker for MML patients (54). miR-222 in exosome can mediate transfer and sufficiently increase MML malignancy (55).

\section{INFLAMMATORY DISEASES}

The miR-221/222 is also involved in the pathogenesis of some inflammatory diseases, such as rheumatoid arthritis and atherosclerosis. The miR-221/222 has been found to be overexpressed in rheumatoid arthritis synovial fibroblasts, serum, and synovial tissues of patients with rheumatoid arthritis $(56,57)$. Furthermore, downregulation of miR-221 in fibroblast-like synoviocytes could significantly inhibit the expression of pro-inflammatory cytokines and chemokine, inhibit cell migration and invasion, and induce cell apoptosis via inhibiting vascular endothelial growth factor (VEGF), matrix metalloproteinase-3 (MMP-3), and matrix metalloproteinase-9 (MMP-9) (56). The overexpression of miR-221 can also decrease the level of BMP2, p-Smads, and osteogenic genes in degenerated annulus fibrosus cells (106). Overexpression of miR-221-inhibited adiponectin-stimulated nitric oxide (NO) in HUVECs indicated that miR-221 targeted AdipoR1 to regulate endothelial inflammatory response (58).

Serum miR-221/222 level significantly changed in patients with carotid atherosclerosis and coronary artery disease, thereby suggesting that they might be potential diagnostic biomarkers $(59,60)$. Xue et al. have found that overexpression of miR-19b and miR-221/222 in human aortic endothelial cells can induce reactive oxygen species (ROS) overproduction, which eventually leads to cell apoptosis and contributes to the pathogenesis of atherosclerosis (61). Moreover, inhibition of miR-19b and miR-221/222 expression with miRNA inhibitors can ameliorate the inflammation-induced cellular ROS production by regulating peroxisome proliferator-activated receptor- $\gamma$ coactivator- $1 \alpha$ (PGC-1 $\alpha$ ), thereby suggesting that these three miRNAs may be the potential therapeutic targets for atherosclerosis and coronary restenosis (61). The miR-221/-222 cluster orchestrates the antiviral and inflammatory immune response to viral infection of the heart, which demonstrated that the inhibition of miR-221/-222 increases viral load, inflammation, and overall cardiac injury upon viral myocarditis (107). It has been reported that miR-221 can suppress NO synthesis and activate nuclear factor-kappa B (NF- $\mathrm{BB})$ signaling in human umbilical vein endothelial cells by targeting adiponectin receptor (AdipoR1), thereby suggesting that miR-221 might be involved in regulating endothelial inflammation response in vascular diseases (such as atherosclerosis) (58).

\section{DISCUSSION}

The discovery of the important roles of miR-221/222 in cancer and inflammatory diseases has shown great potential in both 
basic research and clinical applications. As one of the cancer biomarkers, miR-221/222 should be given more attention because of its wide existence and high correlation with cancer and inflammatory diseases. In this review, we have focused on the recent advances related to miR-221/222 for the diagnosis, prognosis, and therapy in breast cancer, liver cancer, pancreatic cancer, prostate cancer, gastric cancer, CRC, glioma, MM, MML, and inflammatory diseases.

miR-221/222 is overexpressed in breast cancer, liver cancer, pancreatic cancer, prostate cancer, gastric cancer, CRC, glioma, MM, and MML (54). Furthermore, miR-221/222 is almost undetectable in normal human melanocytes and is increasingly expressed in the cancers (54). miR-221/222 may mediate the functions of cancer cells to proliferate, differentiate, and invade (Figure 1). Therefore, high levels of miR-221/222 in serum may be useful as a prognostic marker and develop some new diagnosis and prognosis methods for the cancers; and inhibition or silence miR-221/222 may develop some treatment methods for the cancers.

Inflammation is causally linked to numerous clinical pathologies, including cancer, heart disease, and type 2 diabetes. Proinflammatory macrophages have been widely implicated in the initiation and progression of these diseases and therefore are a key target for therapeutic intervention. miR-221/222 families play crucial roles in these diseases through different signaling pathways by regulating the expression of different proteins. For example, miR-221/222 regulates endothelial nitric oxide synthase protein levels after Dicer silencing targeting c-Kit for the inhibition of angiogenesis. Autophagic signaling networks are modulated by miR-221/222 in cancer. In inflammatory diseases,
miR-221/222 expression leads to the inhibition of VEGF, MMP3 , and MMP-9; ROS overproduction by regulating PGC- $1 \alpha$; suppression of NO synthesis; and activation of NF- $\mathrm{\kappa B}$ signaling by targeting AdipoR, thereby regulating the endothelial inflammatory response. Since miR-221/222 families have extensively been studied in cancer network and inflammatory diseases, we consider that miR-221/222 acts as promising biomarkers for cancer and inflammatory diseases and it would offer a new way in molecular targeting cancer treatment. Like other miRNAs, the miR-221/222 cluster plays a remarkable role in cancer and inflammatory diseases. Due to the complexity in diagnosis and treatment of these diseases, miR-221/222 has great potential value as a new biomarker. A combined use of miR-221/222 and other tumor biomarkers will maximum benefit the diagnosis, prognosis, and treatment.

The serum level of miR-221/222 will be useful as a prognostic marker and develop some new diagnosis and prognosis methods for some cancers and inflammatory diseases; if the serum level of miR-221/222 significantly increases than in healthy controls, they should be considered cancer candidates; and inhibition, control, or silence miR-221/222 will develop some treatment methods for the cancers.

\section{CONCLUSION}

In this review, we focused on each disease for a comprehensive analysis, which is different from previous reviews. Current results in the literature suggest that miR-221/222 has the potential to be considered as novel diagnostic and prognostic biomarkers for these diseases. Moreover, particular attention should be given to

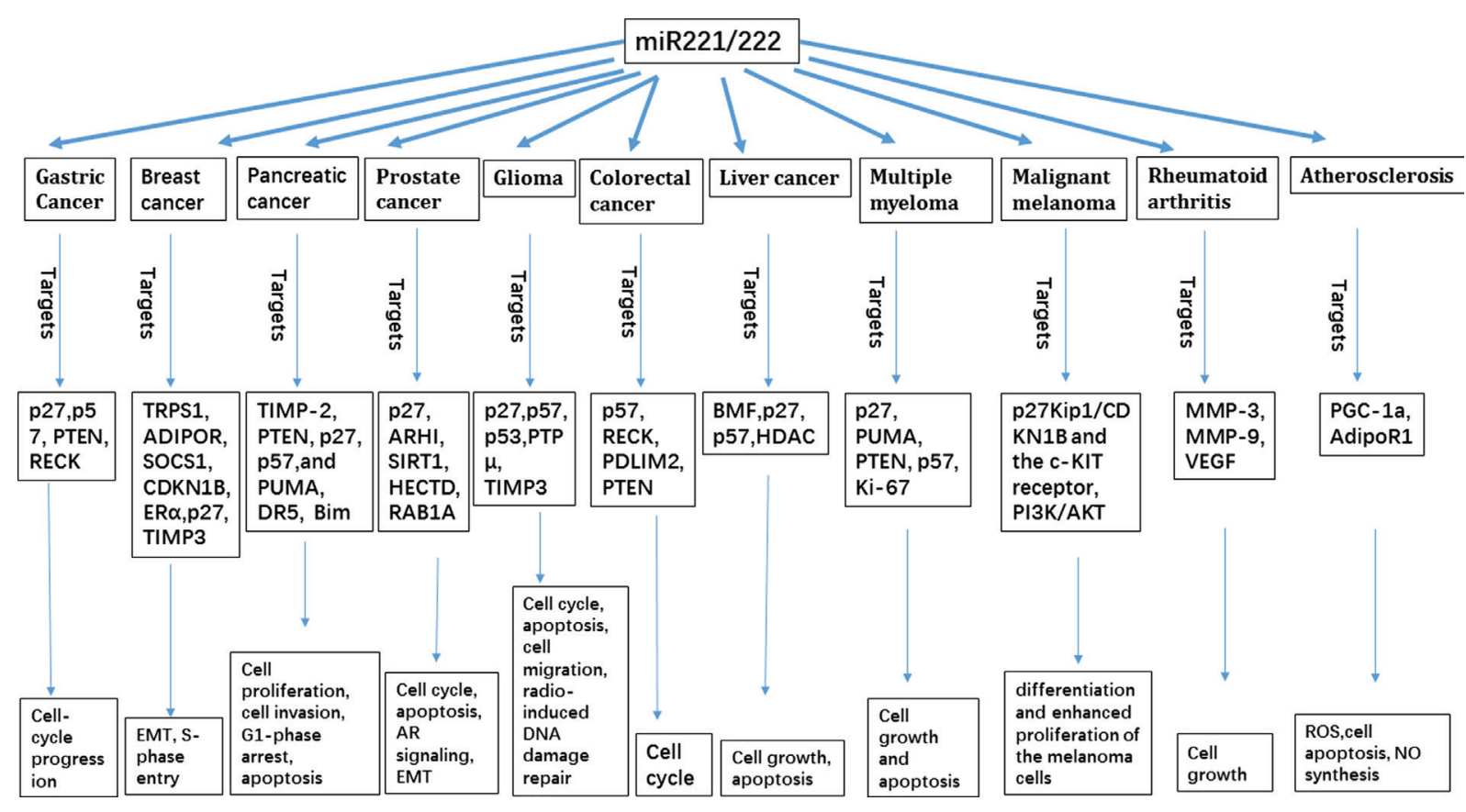

FIGURE 1 | Schema summarizing the different cellular pathways targeted by miR-121/122. 
the gene therapies based on miR-221/222 for the development of novel therapeutics for cancer and inflammatory diseases.

\section{AUTHOR CONTRIBUTIONS}

WY, JS, CF, and YC conceived and participated in its design, searched databases, extracted and assessed studies, and helped to draft the manuscript. JS, YO, JC, XL, YZ, KY, XZ, YC, WY, and CF participated in the conceptualization, data extraction, and analysis. JS wrote the manuscript, and WY conceived the initial idea and the conceptualization, participated in the data extraction and analysis, and revised the manuscript. All the authors read and approved the final manuscript.

\section{REFERENCES}

1. Dalmay T. Mechanism of miRNA-mediated repression of mRNA translation. Essays Biochem (2013) 54:29-38. doi:10.1042/bse0540029

2. Ambros V. The functions of animal microRNAs. Nature (2004) 431:350-5. doi:10.1038/nature02871

3. Auyeung VC, Ulitsky I, McGeary SE, Bartel DP. Beyond secondary structure: primary-sequence determinants license pri-miRNA hairpins for processing. Cell (2013) 152:844-58. doi:10.1016/j.cell.2013.01.031

4. Han J, Lee Y, Yeom KH, Nam JW, Heo I, Rhee JK, et al. Molecular basis for the recognition of primary microRNAs by the Drosha-DGCR8 complex. Cell (2006) 125:887-901. doi:10.1016/j.cell.2006.03.043

5. Bartel DP. microRNAs: genomics, biogenesis, mechanism, and function. Cell (2004) 116:281-97. doi:10.1016/S0092-8674(04)00045-5

6. Rana TM. Illuminating the silence: understanding the structure and function of small RNAs. Nat Rev Mol Cell Biol (2007) 8:23-36. doi:10.1038/ nrm2085

7. Cho WC. Exploiting the therapeutic potential of microRNAs in human cancer. Expert Opin Ther Targets (2012) 16:345-50. doi:10.1517/14728222. 2012.663354

8. Cho WC. microRNAs: potential biomarkers for cancer diagnosis, prognosis and targets for therapy. Int J Biochem Cell Biol (2010) 42:1273-81. doi:10.1016/j.biocel.2009.12.014

9. Ma L, Wei L, Wu F, Hu Z, Liu Z, Yuan W. Advances with microRNAs in Parkinson's disease research. Drug Des Devel Ther (2013) 7:1103-13. doi:10.2147/DDDT.S48500

10. Galardi S, Mercatelli N, Giorda E, Massalini S, Frajese GV, Ciafrè SA, et al. miR-221 and miR-222 expression affects the proliferation potential of human prostate carcinoma cell lines by targeting p27Kip1. J Biol Chem (2007) 282:23716-24. doi:10.1074/jbc.M701805200

11. Song Z, Li G. Role of specific microRNAs in regulation of vascular smooth muscle cell differentiation and the response to injury. J Cardiovasc Transl Res (2010) 3:246-50. doi:10.1007/s12265-010-9163-0

12. Kuehbacher A, Urbich C, Dimmeler S. Targeting microRNA expression to regulate angiogenesis. Trends Pharmacol Sci (2008) 29:12-5. doi:10.1016/ j.tips.2007.10.014

13. Chistiakov DA, Sobenin IA, Orekhov AN, Bobryshev YV. Human miR221/222 in physiological and atherosclerotic vascular remodeling. Biomed Res Int (2015) 2015:354517. doi:10.1155/2015/354517

14. Rippe C, Blimline M, Magerko KA, Lawson BR, LaRocca TJ, Donato AJ, et al. microRNA changes in human arterial endothelial cells with senescence: relation to apoptosis, eNOS and inflammation. Exp Gerontol (2012) 47:45-51. doi:10.1016/j.exger.2011.10.004

15. Stinson S, Lackner MR, Adai AT, Yu N, Kim HJ, O’Brien C, et al. miR-221/222 targeting of trichorhinophalangeal 1 (TRPS1) promotes epithelial-to-mesenchymal transition in breast cancer. Sci Signal (2011) 4:2002258. doi:10.1126/ scisignal.2002258

16. Hwang MS, Yu N, Stinson SY, Yue P, Newman RJ, Allan BB, et al. miR-221/222 targets adiponectin receptor 1 to promote the epithelial-to-mesenchymal transition in breast cancer. PLoS One (2013) 8:e66502. doi:10.1371/journal. pone.0066502

\section{FUNDING}

This study was funded by the Grants from National Natural Science Foundation of China (No. 81570992, and 81571261), Industry-University-Institute-Medicine Cooperation Foundation of Shanghai (12DZDZ1940303), the Interdisciplinary Projects of Medicine and Engineering of Shanghai JiaoTong University (No. YG2013MS52, YG2014QN06, YG2013MS62, and YG2015MS06), SUMHS Seed Foundation Project (No. HMSF16-21-010), Natural Science Foundation of Shanghai, China (15ZR1432500), and Science and Technology Development Foundation of Pudong New District, Shanghai, China (PKJ2016-Y55).

17. Li Y, Liang C, Ma H, Zhao Q, Lu Y, Xiang Z, et al. miR-221/222 promotes S-phase entry and cellular migration in control of basal-like breast cancer. Molecules (2014) 19:7122-37. doi:10.3390/molecules 19067122

18. Gan R, Yang Y, Yang X, Zhao L, Lu J, Meng QH. Downregulation of miR$221 / 222$ enhances sensitivity of breast cancer cells to tamoxifen through upregulation of TIMP3. Cancer Gene Ther (2014) 21:290-6. doi:10.1038/ cgt.2014.29

19. Pichiorri F, Palmieri D, De Luca L, Consiglio J, You J, Rocci A, et al. In vivo NCL targeting affects breast cancer aggressiveness through miRNA regulation. J Exp Med (2013) 210:951-68. doi:10.1084/jem.20120950

20. Falkenberg N, Anastasov N, Rappl K, Braselmann H, Auer G, Walch A, et al. miR-221/-222 differentiate prognostic groups in advanced breast cancers and influence cell invasion. Br J Cancer (2013) 109:2714-23. doi:10.1038/ bjc. 2013.625

21. Gramantieri L, Fornari F, Ferracin M, Veronese A, Sabbioni S, Calin GA, et al. microRNA-221 targets Bmf in hepatocellular carcinoma and correlates with tumor multifocality. Clin Cancer Res (2009) 15:5073-81. doi:10.1158/10780432.CCR-09-0092

22. Bae HJ, Jung KH, Eun JW, Shen Q, Kim HS, Park SJ, et al. microRNA-221 governs tumor suppressor HDAC6 to potentiate malignant progression of liver cancer. J Hepatol (2015) 63:408-19. doi:10.1016/j.jhep.2015.03.019

23. Callegari E, Elamin BK, Giannone F, Milazzo M, Altavilla G, Fornari F, et al. Liver tumorigenicity promoted by microRNA-221 in a mouse transgenic model. Hepatology (2012) 56:1025-33. doi:10.1002/hep.25747

24. Li J, Wang Y, Yu W, Chen J, Luo J. Expression of serum miR-221 in human hepatocellular carcinoma and its prognostic significance. Biochem Biophys Res Commun (2011) 406:70-3. doi:10.1016/j.bbrc.2011.01.111

25. Xu Q, Li P, Chen X, Zong L, Jiang Z, Nan L, et al. miR-221/222 induces pancreatic cancer progression through the regulation of matrix metalloproteinases. Oncotarget (2015) 6:14153-64. doi:10.18632/oncotarget.3686

26. Sarkar S, Dubaybo H, Ali S, Goncalves P, Kollepara SL, Sethi S, et al. Downregulation of miR-221 inhibits proliferation of pancreatic cancer cells through up-regulation of PTEN, p27(kip1), p57(kip2), and PUMA. Am J Cancer Res (2013) 3:465-77.

27. Passadouro M, Pedroso de Lima MC, Faneca H. microRNA modulation combined with sunitinib as a novel therapeutic strategy for pancreatic cancer. Int J Nanomedicine (2014) 9:3203-17. doi:10.2147/IJN.S64456

28. Tanaka R, Tomosugi M, Horinaka M, Sowa Y, Sakai T. Metformin causes G1-phase arrest via down-regulation of miR-221 and enhances trail sensitivity through DR5 up-regulation in pancreatic cancer cells. PLoS One (2015) 10:e0125779. doi:10.1371/journal.pone.0125779

29. Lee C, He H, Jiang Y, Di Y, Yang F, Li J, et al. Elevated expression of tumor miR-222 in pancreatic cancer is associated with Ki67 and poor prognosis. Med Oncol (2013) 30:700. doi:10.1007/s12032-013-0700-y

30. Yang X, Yang Y, Gan R, Zhao L, Li W, Zhou H, et al. Down-regulation of mir-221 and mir-222 restrain prostate cancer cell proliferation and migration that is partly mediated by activation of SIRT1. PLoS One (2014) 9:e98833. doi:10.1371/journal.pone.0098833

31. Mercatelli N, Coppola V, Bonci D, Miele F, Costantini A, Guadagnoli M, et al. The inhibition of the highly expressed miR-221 and miR-222 impairs 
the growth of prostate carcinoma xenografts in mice. PLoS One (2008) 3:24. doi:10.1371/journal.pone.0004029

32. Sun T, Wang X, He HH, Sweeney CJ, Liu SX, Brown M, et al. miR-221 promotes the development of androgen independence in prostate cancer cells via downregulation of HECTD2 and RAB1A. Oncogene (2014) 33:2790-800. doi:10.1038/onc.2013.230

33. Zhang C, Zhang J, Hao J, Shi Z, Wang Y, Han L, et al. High level of miR221/222 confers increased cell invasion and poor prognosis in glioma. J Transl Med (2012) 10:119. doi:10.1186/1479-5876-10-119

34. Kim YK, Yu J, Han TS, Park SY, Namkoong B, Kim DH, et al. Functional links between clustered microRNAs: suppression of cell-cycle inhibitors by microRNA clusters in gastric cancer. Nucleic Acids Res (2009) 37:1672-81. doi:10.1093/nar/gkp002

35. Liu W, Song N, Yao H, Zhao L, Liu H, Li G. miR-221 and miR-222 simultaneously target RECK and regulate growth and invasion of gastric cancer cells. Med Sci Monit (2015) 21:2718-25. doi:10.12659/MSM.894324

36. Chun-Zhi Z, Lei H, An-Ling Z, Yan-Chao F, Xiao Y, Guang-Xiu W, et al. microRNA-221 and microRNA-222 regulate gastric carcinoma cell proliferation and radioresistance by targeting PTEN. BMC Cancer (2010) 10:367. doi:10.1186/1471-2407-10-367

37. Song MY, Pan KF, Su HJ, Zhang L, Ma JL, Li JY, et al. Identification of serum microRNAs as novel non-invasive biomarkers for early detection of gastric cancer. PLoS One (2012) 7:14. doi:10.1371/journal.pone.0033608

38. Fu Z, Qian F, Yang X, Jiang H, Chen Y, Liu S. Circulating miR-222 in plasma and its potential diagnostic and prognostic value in gastric cancer. Med Oncol (2014) 31:164. doi:10.1007/s12032-014-0164-8

39. Sun K, Wang W, Zeng JJ, Wu CT, Lei ST, Li GX. microRNA-221 inhibits CDKN1C/p57 expression in human colorectal carcinoma. Acta Pharmacol $\operatorname{Sin}$ (2011) 32:375-84. doi:10.1038/aps.2010.206

40. Qin J, Luo M. microRNA-221 promotes colorectal cancer cell invasion and metastasis by targeting RECK. FEBS Lett (2014) 588:99-104. doi:10.1016/ j.febslet.2013.11.014

41. Liu S, Sun X, Wang M, Hou Y, Zhan Y, Jiang Y, et al. A microRNA 221- and 222-mediated feedback loop maintains constitutive activation of NFkB and STAT3 in colorectal cancer cells. Gastroenterology (2014) 147:847-59.e11. doi:10.1053/j.gastro.2014.06.006

42. Xue Q, Sun K, Deng HJ, Lei ST, Dong JQ, Li GX. Anti-miRNA-221 sensitizes human colorectal carcinoma cells to radiation by upregulating PTEN. World J Gastroenterol (2013) 19:9307-17. doi:10.3748/wjg.v19.i48.9307

43. Pu XX, Huang GL, Guo HQ, Guo CC, Li H, Ye S, et al. Circulating miR-221 directly amplified from plasma is a potential diagnostic and prognostic marker of colorectal cancer and is correlated with p53 expression. J Gastroenterol Hepatol (2010) 25:1674-80. doi:10.1111/j.1440-1746.2010.06417.x

44. Medina R, Zaidi SK, Liu CG, Stein JL, van Wijnen AJ, Croce CM, et al. microRNAs 221 and 222 bypass quiescence and compromise cell survival. Cancer Res (2008) 68:2773-80. doi:10.1158/0008-5472.CAN-07-6754

45. Zhang C, Kang C, You Y, Pu P, Yang W, Zhao P, et al. Co-suppression of miR-221/222 cluster suppresses human glioma cell growth by targeting p27kip1 in vitro and in vivo. Int J Oncol (2009) 34:1653-60. doi:10.3892/ ijo_00000296

46. Zhang CZ, Zhang JX, Zhang AL, Shi ZD, Han L, Jia ZF, et al. miR-221 and miR-222 target PUMA to induce cell survival in glioblastoma. Mol Cancer (2010) 9:229. doi:10.1186/1476-4598-9-229

47. Quintavalle C, Garofalo M, Zanca C, Romano G, Iaboni M, del Basso De Caro M, et al. miR-221/222 overexpression in human glioblastoma increases invasiveness by targeting the protein phosphate PTP $\mu$. Oncogene (2012) 31:858-68. doi:10.1038/onc.2011.280

48. Chen L, Zhang J, Han L, Zhang A, Zhang C, Zheng Y, et al. Downregulation of miR-221/222 sensitizes glioma cells to temozolomide by regulating apoptosis independently of p53 status. Oncol Rep (2012) 27:854-60. doi:10.3892/ or.2011.1535

49. Li W, Guo F, Wang P, Hong S, Zhang C. miR-221/222 confers radioresistance in glioblastoma cells through activating Akt independent of PTEN status. Curr Mol Med (2014) 14:185-95. doi:10.2174/1566524013666131203103147

50. Di Martino MT, Gullà A, Cantafio ME, Lionetti M, Leone E, Amodio N, et al. In vitro and in vivo anti-tumor activity of miR-221/222 inhibitors in multiple myeloma. Oncotarget (2013) 4:242-55. doi:10.18632/oncotarget.820

51. Di Martino MT, Gullà A, Gallo Cantafio ME, Altomare E, Amodio N, Leone E, et al. In vitro and in vivo activity of a novel locked nucleic acid
(LNA)-inhibitor-miR-221 against multiple myeloma cells. PLoS One (2014) 9:e89659. doi:10.1371/journal.pone.0089659

52. Gullà A, Di Martino MT, Gallo Cantafio ME, Morelli E, Amodio N, Botta C, et al. A 13 mer LNA-i-miR-221 inhibitor restores drug sensitivity in melphalan-refractory multiple myeloma cells. Clin Cancer Res (2016) 22:1222-33. doi:10.1158/1078-0432.CCR-15-0489

53. Huang JJ, Yu J, Li JY, Liu YT, Zhong RQ. Circulating microRNA expression is associated with genetic subtype and survival of multiple myeloma. Med Oncol (2012) 29:2402-8. doi:10.1007/s12032-012-0210-3

54. Kanemaru H, Fukushima S, Yamashita J, Honda N, Oyama R, Kakimoto A, et al. The circulating microRNA-221 level in patients with malignant melanoma as a new tumor marker. J Dermatol Sci (2011) 61(3):187-93. doi:10.1016/j.jdermsci.2010.12.010

55. Felicetti F, De Feo A, Coscia C, Puglisi R, Pedini F, Pasquini L, et al. Exosomemediated transfer of miR-222 is sufficient to increase tumor malignancy in melanoma. J Transl Med (2016) 14:56. doi:10.1186/s12967-016-0811-2

56. Yang S, Yang Y. Downregulation of microRNA221 decreases migration and invasion in fibroblastlike synoviocytes in rheumatoid arthritis. Mol Med Rep (2015) 12:2395-401. doi:10.3892/mmr.2015.3642

57. Pandis I, Ospelt C, Karagianni N, Denis MC, Reczko M, Camps C, et al. Identification of microRNA-221/222 and microRNA-323-3p association with rheumatoid arthritis via predictions using the human tumour necrosis factor transgenic mouse model. Ann Rheum Dis (2012) 71:1716-23. doi:10.1136/ annrheumdis-2011-200803

58. Chen CF, Huang J, Li H, Zhang C, Huang X, Tong G, et al. microRNA-221 regulates endothelial nitric oxide production and inflammatory response by targeting adiponectin receptor 1. Gene (2015) 565:246-51. doi:10.1016/ j.gene.2015.04.014

59. Minami Y, Satoh M, Maesawa C, Takahashi Y, Tabuchi T, Itoh T, et al. Effect of atorvastatin on microRNA 221/ 222 expression in endothelial progenitor cells obtained from patients with coronary artery disease. Eur J Clin Invest (2009) 39:359-67. doi:10.1111/j.1365-2362.2009.02110.x

60. Zhang X, Shao S, Geng H, Yu Y, Wang C, Liu Z, et al. Expression profiles of six circulating microRNAs critical to atherosclerosis in patients with subclinical hypothyroidism: a clinical study. J Clin Endocrinol Metab (2014) 99:E766-74. doi:10.1210/jc.2013-1629

61. Xue Y, WeiZ, Ding H, Wang Q, Zhou Z, Zheng S, et al. microRNA-19b/221/222 induces endothelial cell dysfunction via suppression of PGC-1alpha in the progression of atherosclerosis. Atherosclerosis (2015) 241:671-81. doi:10.1016/j.atherosclerosis.2015.06.031

62. Li B, Lu Y, Wang H, Han X, Mao J, Li J, et al. miR-221/222 enhance the tumorigenicity of human breast cancer stem cells via modulation of PTEN/Akt pathway. Biomed Pharmacother (2016) 79:93-101. doi:10.1016/ j.biopha.2016.01.045

63. Rao X, Di Leva G, Li M, Fang F, Devlin C, Hartman-Frey C, et al. microRNA-221/222 confers breast cancer fulvestrant resistance by regulating multiple signaling pathways. Oncogene (2011) 30:1082-97. doi:10.1038/ onc. 2010.487

64. Miller TE, Ghoshal K, Ramaswamy B, Roy S, Datta J, Shapiro CL, et al. microRNA-221/222 confers tamoxifen resistance in breast cancer by targeting p27Kip1. J Biol Chem (2008) 283:29897-903. doi:10.1074/jbc. M804612200

65. Zhao JJ, Lin J, Yang H, Kong W, He L, Ma X, et al. microRNA-221/222 negatively regulates estrogen receptor alpha and is associated with tamoxifen resistance in breast cancer. J Biol Chem (2008) 283:31079-86. doi:10.1074/ jbc.M806041200

66. Wei Y, Lai X, Yu S, Chen S, Ma Y, Zhang Y, et al. Exosomal miR-221/222 enhances tamoxifen resistance in recipient ER-positive breast cancer cells. Breast Cancer Res Treat (2014) 147:423-31. doi:10.1007/s10549-014-3037-0

67. Di Leva G, Gasparini P, Piovan C, Ngankeu A, Garofalo M, Taccioli C, et al. microRNA cluster 221-222 and estrogen receptor alpha interactions in breast cancer. J Natl Cancer Inst (2010) 102:706-21. doi:10.1093/jnci/djq102

68. Farazi TA, Horlings HM, Ten Hoeve JJ, Mihailovic A, Halfwerk H, Morozov $\mathrm{P}$, et al. microRNA sequence and expression analysis in breast tumors by deep sequencing. Cancer Res (2011) 71:4443-53. doi:10.1158/0008-5472. CAN-11-0608

69. Martello G, Rosato A, Ferrari F, Manfrin A, Cordenonsi M, Dupont S, et al. A microRNA targeting dicer for metastasis control. Cell (2010) 141:1195-207. doi:10.1016/j.cell.2010.05.017 
70. Pickering BF, Yu D, Van Dyke MW. Nucleolin protein interacts with microprocessor complex to affect biogenesis of microRNAs 15a and 16. J Biol Chem (2011) 286:44095-103. doi:10.1074/jbc.M111.265439

71. Ogawa T, Enomoto M, Fujii H, Sekiya Y, Yoshizato K, Ikeda K, et al. microRNA-221/222 upregulation indicates the activation of stellate cells and the progression of liver fibrosis. Gut (2012) 61:1600-9. doi:10.1136/ gutjnl-2011-300717

72. Pineau P, Volinia S, McJunkin K, Marchio A, Battiston C, Terris B, et al. miR221 overexpression contributes to liver tumorigenesis. Proc Natl Acad Sci U $S$ A (2010) 107:264-9. doi:10.1073/pnas.0907904107

73. Gramantieri L, Fornari F, Callegari E, Sabbioni S, Lanza G, Croce CM, et al. microRNA involvement in hepatocellular carcinoma. J Cell Mol Med (2008) 12:2189-204. doi:10.1111/j.1582-4934.2008.00533.x

74. Rong M, Chen G, Dang Y. Increased miR-221 expression in hepatocellular carcinoma tissues and its role in enhancing cell growth and inhibiting apoptosis in vitro. BMC Cancer (2013) 13:21. doi:10.1186/1471-2407-13-21

75. Fu X, Wang Q, Chen J, Huang X, Chen X, Cao L, et al. Clinical significance of miR-221 and its inverse correlation with $\mathrm{p} 27 \mathrm{Kip}(1)$ in hepatocellular carcinoma. Mol Biol Rep (2011) 38:3029-35. doi:10.1007/s11033-010-9969-5

76. Ramjaun AR, Tomlinson S, Eddaoudi A, Downward J. Upregulation of two BH3-only proteins, Bmf and Bim, during TGF beta-induced apoptosis. Oncogene (2007) 26:970-81. doi:10.1038/sj.onc.1209852

77. Breuhahn K, Longerich T, Schirmacher P. Dysregulation of growth factor signaling in human hepatocellular carcinoma. Oncogene (2006) 25:3787-800. doi:10.1038/sj.onc. 1209556

78. Fornari F, Milazzo M, Galassi M, Callegari E, Veronese A, Miyaaki H, et al. p53/mdm2 feedback loop sustains miR-221 expression and dictates the response to anticancer treatments in hepatocellular carcinoma. Mol Cancer Res (2014) 12:203-16. doi:10.1158/1541-7786.MCR-13-0312-T

79. He XX, Guo AY, Xu CR, Chang Y, Xiang GY, Gong J, et al. Bioinformatics analysis identifies miR-221 as a core regulator in hepatocellular carcinoma and its silencing suppresses tumor properties. Oncol Rep (2014) 32:1200-10. doi:10.3892/or.2014.3306

80. Lee EJ, Gusev Y, Jiang J, Nuovo GJ, Lerner MR, Frankel WL, et al. Expression profiling identifies microRNA signature in pancreatic cancer. Int J Cancer (2007) 120:1046-54. doi:10.1002/ijc.22394

81. Zhang Y, Li M, Wang H, Fisher WE, Lin PH, Yao Q, et al. Profiling of 95 microRNAs in pancreatic cancer cell lines and surgical specimens by real-time PCR analysis. World J Surg (2009) 33:698-709. doi:10.1007/ s00268-008-9833-0

82. Chen Y, Zaman MS, Deng G, Majid S, Saini S, Liu J, et al. microRNAs 221/222 and genistein-mediated regulation of ARHI tumor suppressor gene in prostate cancer. Cancer Prev Res (2011) 4:76-86. doi:10.1158/1940-6207. CAPR-10-0167

83. Lin D, Cui F, Bu Q, Yan C. The expression and clinical significance of GTPbinding RAS-like 3 (ARHI) and microRNA 221 and 222 in prostate cancer. J Int Med Res (2011) 39:1870-5. doi:10.1177/147323001103900530

84. Wang L, Liu C, Li C, Xue J, Zhao S, Zhan P, et al. Effects of microRNA-221/222 on cell proliferation and apoptosis in prostate cancer cells. Gene (2015) 572:252-8. doi:10.1016/j.gene.2015.07.017

85. Heinlein CA, Chang C. Androgen receptor in prostate cancer. Endocr Rev (2004) 25:276-308. doi:10.1210/er.2002-0032

86. Sun T, Wang Q, Balk S, Brown M, Lee GS, Kantoff P. The role of microRNA-221 and microRNA-222 in androgen-independent prostate cancer cell lines. Cancer Res (2009) 69:3356-63. doi:10.1158/0008-5472.CAN-08-4112

87. Sun T, Yang M, Kantoff P, Lee GS. Role of microRNA-221/-222 in cancer development and progression. Cell Cycle (2009) 8:2315-6. doi:10.4161/ cc.8.15.9221

88. Sun T, Yang M, Chen S, Balk S, Pomerantz M, Hsieh CL, et al. The altered expression of miR-221/-222 and miR-23b/-27b is associated with the development of human castration resistant prostate cancer. Prostate (2012) 72:1093-103. doi:10.1002/pros.22456

89. Du YY, Dai DQ, Yang Z. Role of RECK methylation in gastric cancer and its clinical significance. World J Gastroenterol (2010) 16:904-8. doi:10.3748/ wjg.v16.i7.904

90. Xu L, Dai WQ, Xu XF, Wang F, He L, Guo CY. Effects of multiple-target anti-microRNA antisense oligodeoxyribonucleotides on proliferation and migration of gastric cancer cells. Asian Pac J Cancer Prev (2012) 13:3203-7. doi:10.7314/APJCP.2012.13.7.3203
91. Liu K, Li G, Fan C, Diao Y, Wu B, Li J. Increased Expression of microRNA-221 in gastric cancer and its clinical significance. J Int Med Res (2012) 40:467-74. doi: $10.1177 / 147323001204000208$

92. Ebert MS, Neilson JR, Sharp PA. microRNA sponges: competitive inhibitors of small RNAs in mammalian cells. Nat Methods (2007) 4:721-6. doi:10.1038/ nmeth1079

93. Cai K, Shen F, Cui JH, Yu Y, Pan HQ. Expression of miR-221 in colon cancer correlates with prognosis. Int J Clin Exp Med (2015) 8:2794-8.

94. Yau TO, Wu CW, Dong Y, Tang CM, Ng SS, Chan FK, et al. microRNA-221 and microRNA-18a identification in stool as potential biomarkers for the non-invasive diagnosis of colorectal carcinoma. Br J Cancer (2014) 111:1765-71. doi:10.1038/bjc.2014.484

95. Burgoyne AM, Phillips-Mason PJ, Burden-Gulley SM, Robinson S, Sloan AE, Miller RH, et al. Proteolytic cleavage of protein tyrosine phosphatase mu regulates glioblastoma cell migration. Cancer Res (2009) 69:6960-8. doi:10.1158/0008-5472.CAN-09-0863

96. Burgoyne AM, Palomo JM, Phillips-Mason PJ, Burden-Gulley SM, Major DL, Zaremba A, et al. PTPmu suppresses glioma cell migration and dispersal. Neuro Oncol (2009) 11:767-78. doi:10.1215/15228517-2009-019

97. Zhang R, Pang B, Xin T, Guo H, Xing Y, Xu S, et al. Plasma miR-221/222 family as novel descriptive and prognostic biomarkers for glioma. Mol Neurobiol (2016) 53:1452-60. doi:10.1007/s12035-014-9079-9

98. Brognara E, Fabbri E, Bazzoli E, Montagner G, Ghimenton C, Eccher A, et al. Uptake by human glioma cell lines and biological effects of a peptidenucleic acids targeting miR-221. J Neurooncol (2014) 118:19-28. doi:10.1007/ s11060-014-1405-6

99. Stupp R, Mason WP, van den Bent MJ, Weller M, Fisher B, Taphoorn MJ, et al. Radiotherapy plus concomitant and adjuvant temozolomide for glioblastoma. N Engl J Med (2005) 352:987-96. doi:10.1056/NEJMoa043330

100. Linz U. Commentary on effects of radiotherapy with concomitant and adjuvant temozolomide versus radiotherapy alone on survival in glioblastoma in a randomised phase III study: 5-year analysis of the EORTC-NCIC trial (Lancet Oncol. 2009; 10:459-466). Cancer (2010) 116:1844-6. doi:10.1002/cncr.24950

101. Quintavalle C, Mangani D, Roscigno G, Romano G, Diaz-Lagares A, Iaboni $\mathrm{M}$, et al. miR-221/222 target the DNA methyltransferase MGMT in glioma cells. PLoS One (2013) 8:e74466. doi:10.1371/journal.pone.0074466

102. Lionetti M, Agnelli L, Mosca L, Fabris S, Andronache A, Todoerti K, et al. Integrative high-resolution microarray analysis of human myeloma cell lines reveals deregulated miRNA expression associated with allelic imbalances and gene expression profiles. Genes Chromosomes Cancer (2009) 48:521-31. doi: $10.1002 /$ gcc. 20660

103. Lionetti M, Biasiolo M, Agnelli L, Todoerti K, Mosca L, Fabris S, et al. Identification of microRNA expression patterns and definition of a microRNA/mRNA regulatory network in distinct molecular groups of multiple myeloma. Blood (2009) 114:e20-6. doi:10.1182/blood-2009-08-237495

104. Rossi M, Di Martino MT, Morelli E, Leotta M, Rizzo A, Grimaldi A, et al. Molecular targets for the treatment of multiple myeloma. Curr Cancer Drug Targets (2012) 12:757-67. doi:10.2174/156800912802429300

105. Anderson KC. Therapeutic advances in relapsed or refractory multiple myeloma. J Natl Compr Canc Netw (2013) 11:676-9.

106. Yeh CH, Jin L, Shen F, Balian G, Li XJ. miR-221 attenuates the osteogenic differentiation of human annulus fibrosus cells. Spine J (2016) 16(7):896-904. doi:10.1016/j.spinee.2016.03.026

107. Corsten M, Heggermont W, Papageorgiou AP, Deckx S, Tijsma A, Verhesen $\mathrm{W}$, et al. The microRNA-221/-222 cluster balances the antiviral and inflammatory response in viral myocarditis. Eur Heart J (2015) 36:2909-19. doi:10.1093/eurheartj/ehv321

Conflict of Interest Statement: The authors declare that the research was conducted in the absence of any commercial or financial relationships that could be construed as a potential conflict of interest.

Copyright (c) 2017 Song, Ouyang, Che, Li, Zhao, Yang, Zhao, Chen, Fan and Yuan. This is an open-access article distributed under the terms of the Creative Commons Attribution License (CC BY). The use, distribution or reproduction in other forums is permitted, provided the original author(s) or licensor are credited and that the original publication in this journal is cited, in accordance with accepted academic practice. No use, distribution or reproduction is permitted which does not comply with these terms. 